\title{
TOWARDS A PROBABILISTIC FLOOD BASE MODEL FOR CARIBBEAN COASTS
}

\author{
Carol Subrath-Ali ${ }^{1}$; Deborah Villarroel-Lamb ${ }^{2}$; Ilan Kelman ${ }^{3}$
}

\begin{abstract}
An estimate of the total water level setup at the coast is examined at a monthly resolution to assess the base combined contribution from wind, wave and pressure setup in the absence of cyclonic activity. A stochastic approach is used to estimat $\mathrm{e}$ the total values of water level setup from the three parameters and the results indicate that while the total coastal water level set up closely follows the wave setup due to a difference of an order of magnitude of two with the wind and pressure set up fro $\mathrm{m}$ the inverse barometer effect, the latter two parameters have a greater impact during the first seven months of the year - the dry season with an approximate two month overlap into the rainy season. Using the generated moments from monthly combined probability density functions, we show that the average coastal setup from the three driving forces show a general decreasing trend from the highest coastal setup months of December, January and February.
\end{abstract}

Key words: coastal setup, probabilitydistributions

\section{INTRODUCTION}

Coastal flooding may be brought on by extreme events in the short term. The degree of flooding may depend however, on the initial water levels driven by factors that may themselves, be not extreme; such as wave setup, wind setup, variation in atmospheric pressure loading and river discharge. The non-systemic nature of setup can contribute to temporal variation in the short term basis (taken here as monthly or less) in the water levels.

The estimate of the combined setup from these driving factors provides a quantitative contribution to the total coastal water level elevations that determines a flood base. Throughout any given year, at any given locality, the estimation of the level of this potential flood base is inbuilt with some measure of uncertainty because of different factors such as topography, coastline exposure and the variability of the driving factors themselves. This may be further compounded by the inclusion of sea level rise and other synoptic drivers.

In the eastern Caribbean region, the archipelago (Figure 1) comprises mainly small islands, classified more popularly as SIDS (Small Island Developing States).

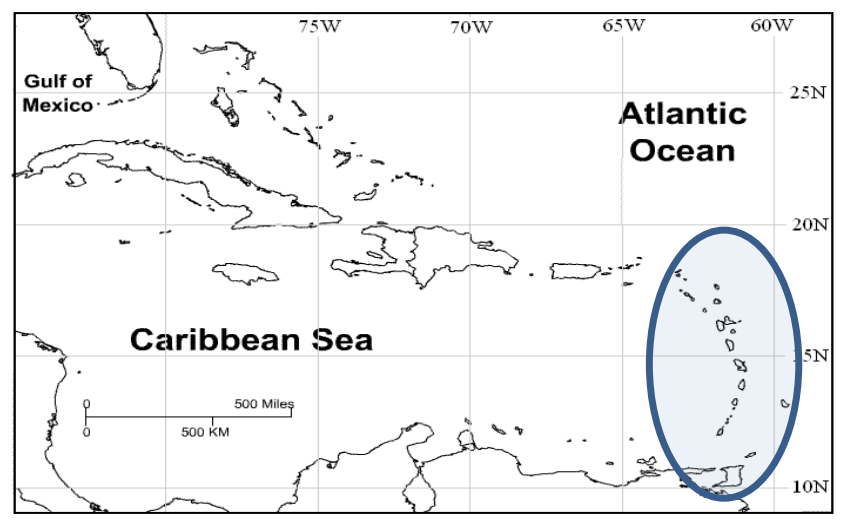

Figure 1. Eastern Caribbean archipelago (source: sheppardsof tw are.com)

These islands, on the leeward side of the Atlantic Ocean are exposed to several coastal hazards which may cause significant sea level elevations such as storm surges from Atlantic Tropical Cyclones during the hurricane season which runs from June $1^{\text {st }}$ to November $30^{\text {th }}$ every year. The variation in the effects of the forcing mechanisms provides a base for such coastal flood events. Because there is a significant scarcity of observed sea level data with respect to the spatial distribution of the sea surface within the Caribbean region. This is further compounded by the fact that the combination of these effects cannot be easily or directly measured; a stochastic model may then provide the best estimates of the sea surface height variation from the combined factors.

\footnotetext{
1; 2 Department of Civil and Environmental Engineering, Faculty of Engineering, University of the West Indies, St. Augustine, Trinidad

${ }^{3}$ Center for International Climate and Environmental Research -Oslo (CICERO)
} 
While the different coastal setup drivers have been examined individually, the combination of the effects is not known. This problem is addressed here by the use of stochastic simulation in a Monte Carlo approach, where the problem solving technique estimates the probabilities of water level elevations from the different factors and provides monthly probability distribution functions from simulation techniques using the generated moments from the respective probability densities of setup.

The goal of this work is to investigate the monthly variation in the combined contribution on the islands of the Caribbean archipelago. The first of the three listed setup parameters: wind, waves and pressure are investigated on a seasonal basis. The analyses of two sample months (one from each of the two Caribbean seasons) are presented in detail and the results from the analysed data sets for the year 2009 are presented following the sample months. The applicability of the results of the model based on the combined setup magnitudes lies in the use of the results in a predictive approach to establish base water level conditions.

The paper is structured so that it presents a review of the existing numerical models that can be used deterministically to estimate the relevant setup with the selection of a particular model, the use of the deterministic components to develop a stochastic model, followed by an analysis of the respective models for each of the representative seasons. A discussion of the analysis is then presented and the paper concludes on the results from the analysis.

\section{BACKGROUND}

There are two major seasons in the Caribbean region. The lower levels of precipitation during the months of January to May characterise the dry season and higher levels of precipitation during the months of June to December generally characterise the wet or rainy season. A subset of the rainy season spanning Ju ne to November holds the Atlantic hurricane season and the monthly boundaries of the respective seasons may represent transition periods.

The coastal setup from wind, waves and variation in the pressure field vary in climatological fashion throughout the year. When higher winter waves in the Atlantic, occur at high latitudes (Dattatri, Raman, and Shankar 1979; Bacon 1978), the generated swells propagate into the Caribbean from the north and there is a marked seasonal variation in wave height; the magnitude of which leads to severe erosion (Bacon 1978). These swell waves are most often experienced in the Caribbean between the months of October and April (Cambers 1998). These breaking waves produce in the surf zone, a temporary elevation in the mean water levels known as wave setup (Komar 1998; Dean and Walton 2010). While wave setup is now featured in many storm surge prediction models and is a significant contributor to the total coastal water level, the contribution is not only limited to the duration of storm events. The breaking waves produce temporary variations in water levels throughout the year.

The wind field in the Caribbean region, governed by the north easterly trades, directly influences the wind sea. Speeds are generally are highest between June to July and from December to March (Cambers 1998). Wind blowing over a body of water, transfers momentum to the surface layer and moves it in the direction of the wind. This is primarily driven by the shear stresses between the air/water interface. The movement of the water causes a temporary decrease in the water level upwind and a piling of water mass downwind or on the leeward side along the direction of flow. The latter is a phenomenon known as wind set-up. It is essentially a balance between the wind stress and the pressure gradient force (Novak et al. 2010). For the islands of the eastern Caribbean, the water accumulation will be more pronounced on the windward coastlines.

The action of changing atmospheric surface pressure also causes a hydrostatic displacement of the water level. These effects too will vary over the months of the year with the annual seasonal migration of the mid Atlantic high pressure cell, the character of the North Atlantic Oscillation, the passage of baroclinic systems at higher latitudes and the passage of barotropic systems mainly during the wet season as a few major factors. Higher pressures tend to depress the water surface and lower pressures cause the oceanic water bodies to respond by hydrostatic uplift.

\section{DETERMINISTIC FACTORS}

Deterministic models are first applied to calculate the relevant parametric setup. While the random nature of coastal processes necessitates a stochastic approach, to adequately describe the combined setup contribution, a determination of each contributing factor is required. The deterministic estimates yield a starting point or a coastal 
setup base which is then randomly sampled - essentially providing the data for the iterative evaluation of the individual coastal setup parameters.

\section{Wave Setup}

Wave setup is due to the cross-shore gradient in radiation stress during the wave breaking process. As the waves break, there is a transfer of momentum to the water column which leads to a sloping water surface that balances the onshore component of the flux of momentum which leads to the temporary increase in the mean water levels. The wave setup has been described as primarily an increasing monotonic function of wave period and incident wave height, and is not readily measured (Harris 1963). The estimation of setup has been done mainly through parameterization and it has been explored by field investigations which have led to the derivation of several empirical relationships where the wave setup on any coastline in dependent on several factors and many assumptions are made to simplify the parameterisation schemes. Because we seek the general trends of the annual water level variation, initial assumptions are for setup on a monotonic, mild slope beach.

Many of these studies show that the wave setup is dependent on the deep water heights (Bowen, Inman, and Simmons 1968; Hansen 1978; Guza and Thornton 1981; Holman and Sallenger 1985; Davis and Nielsen 1988; King et al. 1990; Greenwood and Osborne 1990; Yanagishima and Katoh 1990). Aside from the 1968 study by Bowen, Inman and Simmons, all of the other relationships were derived for natural beaches. Further, for a dis sipative beach (mild slope) the wave setup was not dependent on the surf similarity ( $\xi$ ) parameter (Guza and Thornton 1981; Hanslow and Nielsen 1993). On intermediate to reflective beaches however, the surf similarity was shown to be a governing factor in determining the wave setup (Bowen, Inman, and Simmons 1968; Holman and Sallenger 1985; Yanagishima and Katoh 1990; Stockdon et al. 2006). The other results were from studies in a lake environment (Greenwood and Osborne 1990), setup at the shoreline (Davis and Nielsen 1988), or returned low values when compared to analytical results (King et al. 1990; Dean and Walton 2010) with low values in some cases for dissipative beaches (Stockdon et al. 2006). Guza and Thornton's (1981) equation provides a simple empirical relation between the wave setup and the incident wave height:

$$
\eta=0.17 H_{o}(1)
$$

where $\eta$ is the wave setup and $H_{o}$ is the deep water wave height.

\section{Wind Setup}

Wind blowing over a body of water, transfers momentum to the surface layer and moves it in the direction of the wind. This is primarily driven by the shear stresses between the air/water interface. The movement of the water causes a temporary decrease in the water level upwind and a piling of water mass downwind. The latter is a phenomenon known as wind set-up. It is essentially a balance between the wind stress and the pressure gradient force (Novak et al. 2010).

While empirical formulae proposed for wind setup have primarily been derived for fetch limited, lake environments (Johnson 1953; Moran 2008), bays and lagoons (Kjerfve 1994), inlets (Saville et al. 1962) and river environments (Gui, Zhang, and Xuzhang 1998), but an equation for wind setup (s) at the coast has also been proposed (TuDelft 2010):

$$
s=0.5 \kappa \frac{U_{10}^{2}}{g h} F \cos \varphi \quad(2) \quad \text { where } \kappa=\mathrm{c}_{\mathrm{w}} \frac{\rho_{\text {air }}}{\rho_{\text {water }}}
$$

$\varphi$ is the direction of wind approach to the coast ( 0 is perpendicular), $\mathrm{U}_{10}$ is the wind speed measured at $10 \mathrm{~m}$ above the mean sea level and the friction factor $\mathrm{c}_{\mathrm{w}}$ lies in the range $(0.8$ to 3.0$) \times 10^{-3}$, as given by Karelse and Van Os (1979) in (TuDelft 2010) with a default of $2 \times 10^{-2}$. For the setup at the coast, the fetch (F) is taken as the width of the shallow zone and the depth (d) is the average depth of the surf zone. This approach removes the "unlimited" fetch problem where the fetch would otherwise be the span of the entire ocean, but has been described as being valid for $\mathrm{d} / \mathrm{F}<0.001$ by Leidraad Rivierdijken II in (TuDelft 2010). For the density of air $\left(\rho_{\text {air }}\right)$ taken as $1.21 \mathrm{~kg} / \mathrm{m}^{3}$ and the density of water $\left(\rho_{\text {water }}\right)$ as $1030 \mathrm{~kg} / \mathrm{m}^{3}$ the value of $\kappa$ is then $2.35 \times 10^{-5}$. 


\section{Atmospheric Pressure Effect}

There is a static response of the sea level to changes in atmospheric pressure. The rise of the sea level in response to falling atmospheric pressure is commonly described as an Inverse Barometric Rise (IBR) effect. This IBR results essentially from a horizontal re-distribution of the oceanic water mass (Chelton and Enfield 1986).

The pressure contribution to the sea level variation, if positive (taken here as a rise) is termed the pressure setup $\left(\eta_{\mathrm{p}}\right)$. This is given by a simplified equation (Harper and Sobey 1983; Inazu et al. 2006):

$$
\eta_{\mathrm{p}}=\frac{-(P-\bar{P})}{\rho g}
$$

where $\mathrm{P}$ - Local Sea Level Pressure and $\overline{\mathrm{P}}$ - Mean Sea Level over the entire basin and the value of $\overline{\mathrm{P}}$ is often taken as a default of $1013 \mathrm{hPa}$.

The IBR effect has been shown to be a function of geographical location, frequency and wave number of the pressure forcing function (Wunsch 1972) and the sea level variations have been shown to mainly exhibit an IB response - with the tropics as an exception (Wunsch 1972; Fu and Pihos 1994). Although the effects of the pressure variation is small in the absence of tropical cyclone activity and is usually considered to be insignificant, or lowest in the tropics (Fu and Pihos 1994) it is an important factor when considering the mean sea level annual variation (Weigel 1964). While the $1 \mathrm{hPa} / 1 \mathrm{~cm}$ IBR 'rule' has been consistent in the literature, the oceanic response times have not. Response times have been given from the order of hours to weeks eg. (Dotsenko and Miklashevskaya 2007; Fu and Pihos 1994; Wunsch and Stammer 1997). A period of twenty four hour over the cyclic diurnal variation is used in this study.

\section{Modelling with Uncertainty}

Since the total contribution to the temporary water level elevations from setup cannot be directly measured. A probabilistic model provides perhaps the best analytical stochastic technique of estimation. To deal with a lack of a comprehensive data set, the use of random sampling can be used to create synthetic data through a Monte Carlo approach. This method has been described as a practical way to sample random variables governed by complicated density functions (Nakamura et al. 2012).

\section{DATA \& METHOD}

Wind, wave and pressure data are sourced from an offshore buoy located in a depth of about 5600m at $14^{\circ} 37.21^{\prime} \mathrm{N} 056^{\circ} 14.97^{\prime} \mathrm{W}$ identified as 4100101 (East of Martinique). Wind and pressure sensors are located at $4.5 \mathrm{~m}$ above mean sea level. Hourly data from this buoy for 2009 is sourced from the French meteorological data authority Météo-France. The wave heights at this depth are converted by using linear wave theory, to nearshore waters just outside the surf zone at an average depth of about $15 \mathrm{~m}$.

The monthly data sets for February and August for 2009 were used as representative of the dry and wet season respectively. This year was selected as there was below-average tropical cyclone activity (Berg and Avila 2010) so as to have minimal effects of extreme events in the data set. Where there were tropical cyclones present, listwise deletion was used to exclude data that would have incorporated the effects of extreme conditions. Data gaps were reduced by linear averaging where possible. The hurricane data set (UNISYS 2011) was cross referenced with weather discussion bulletins from the National Hurricane Center, Miami, USA to establish the presence and effects of cyclonic systems within the Caribbean area.

The existing numerical models that can adequately assess the setup for wave, wind and pressure are applied to the data and the range of setup for the given month is determined. The offshore buoy deep water wave heights are used in equation (1) to calculate the wave setup while wind are pressure setup are calculated based on the deterministic equations ( 2 and 3 ) respectively. The pressure setup is determined across the cyclic diurnal variation using a $24 \mathrm{hr}$ moving average.

The setup values are binned using the number of bins $(k)$ such that $\left(k=1+\log _{2} N\right)$ where $\mathrm{N}$ is the number of data points. Histograms are used to display the density of magnitudes; and the probability distributions for the relevant parametric setup are obtained. This enables the use of a distribution fitting process to formulate the combined effect of the three primary drivers. Using a statistical stochastic simulation technique in a Monte Carlo 
fashion, we then randomly sample the probability distributions for the density of setup magnitudes for each month according to the distribution parameters and repeat this process 10,000 times for each of the driving forces for each month of the year. The randomly selected data items from the three distributions are then combined to give an estimate of the total contribution from the respective drivers at a given sampling instant. The entire combined data set is fitted to an appropriate distribution so that for all the months, probability density functions (PDFs) for the elevations of magnitudes are developed. From these PDFs, we extract the moments of the data to get an estimate of the monthly distribution of the total coastal setup.

\section{RESULTS}

Detailed results are presented for the two sample months, following which are the monthly results for the entire year of 2009.

We first present the results for the dry season month of February. Calculations using the relevant deterministic equations provided the probability densities for the individual coastal setup. The wind, wave and pressure setup density functions (Figure 2) with their respective p-p plots immediately below show a good fit to the modelled distributions with the most scatter reflected in the pressure setup. The relevant distribution for each parametric setup is overlaid on the histogram. The wind setup was found to be best modelled with the Pearson Type 6 distribution, the wave setup by the Dagum 4-parameter and the pressure setup by the Pearson (5) 3-parameter. The pressure distribution reflected the coastal level depressions (negative setup - commonly referred to as setdown).
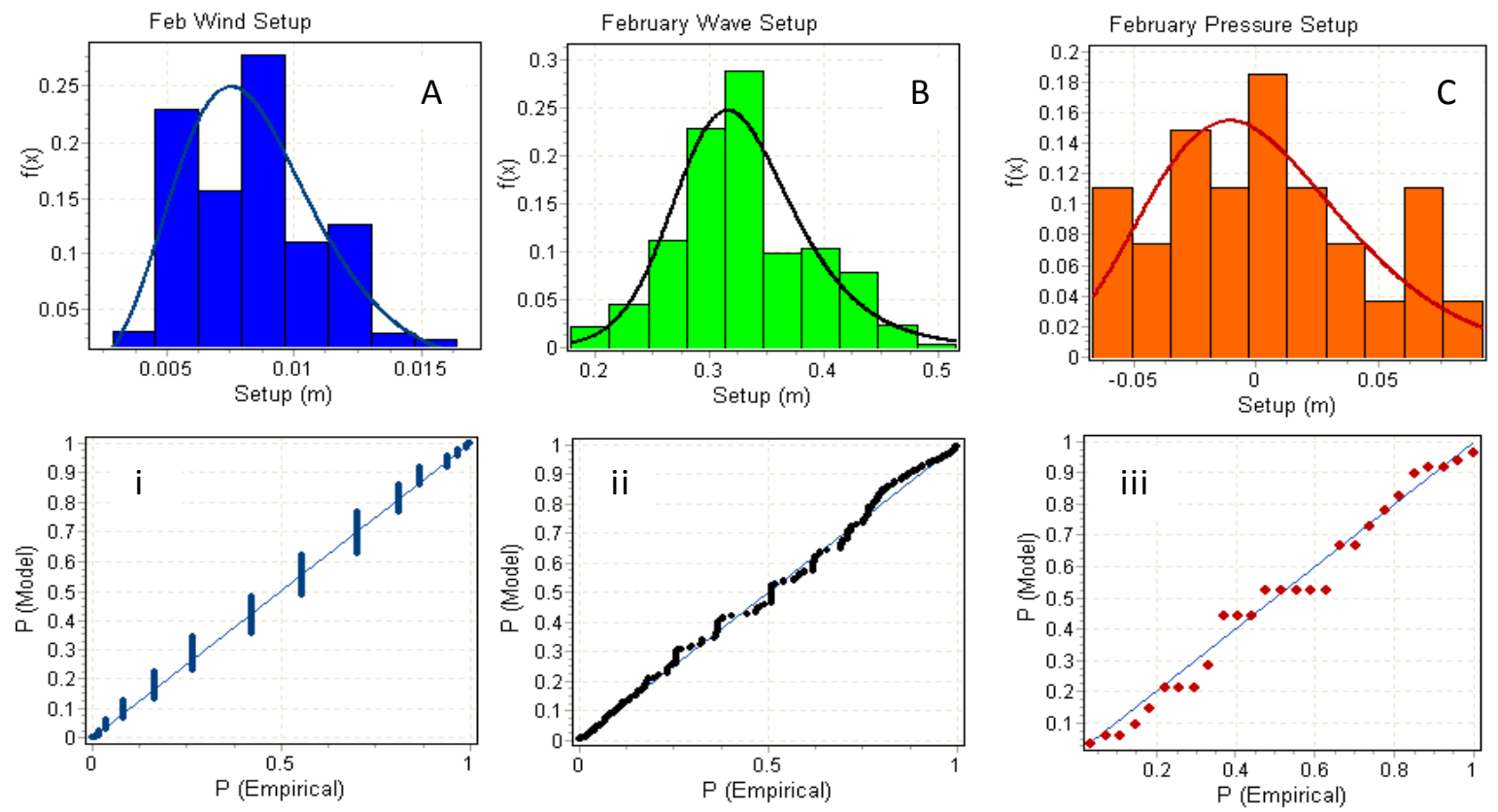

Figure 2. February probability density functions for wind setup (A), wave setup (B) and pressure setup (C) with the respective ( $i$, ii, iii) $p$-p plots showing goodness of fit

The probability density function profiles for August with the respective p-p plots are shown below in Figure 3. The wind setup was best modelled with the Generalised Gamma Function, the wave setup with the Nakagami distribution and the pressure setup with the Generalised Extreme Value. The pressure setup again here showed the most scatter but still presented a relatively good fit. 

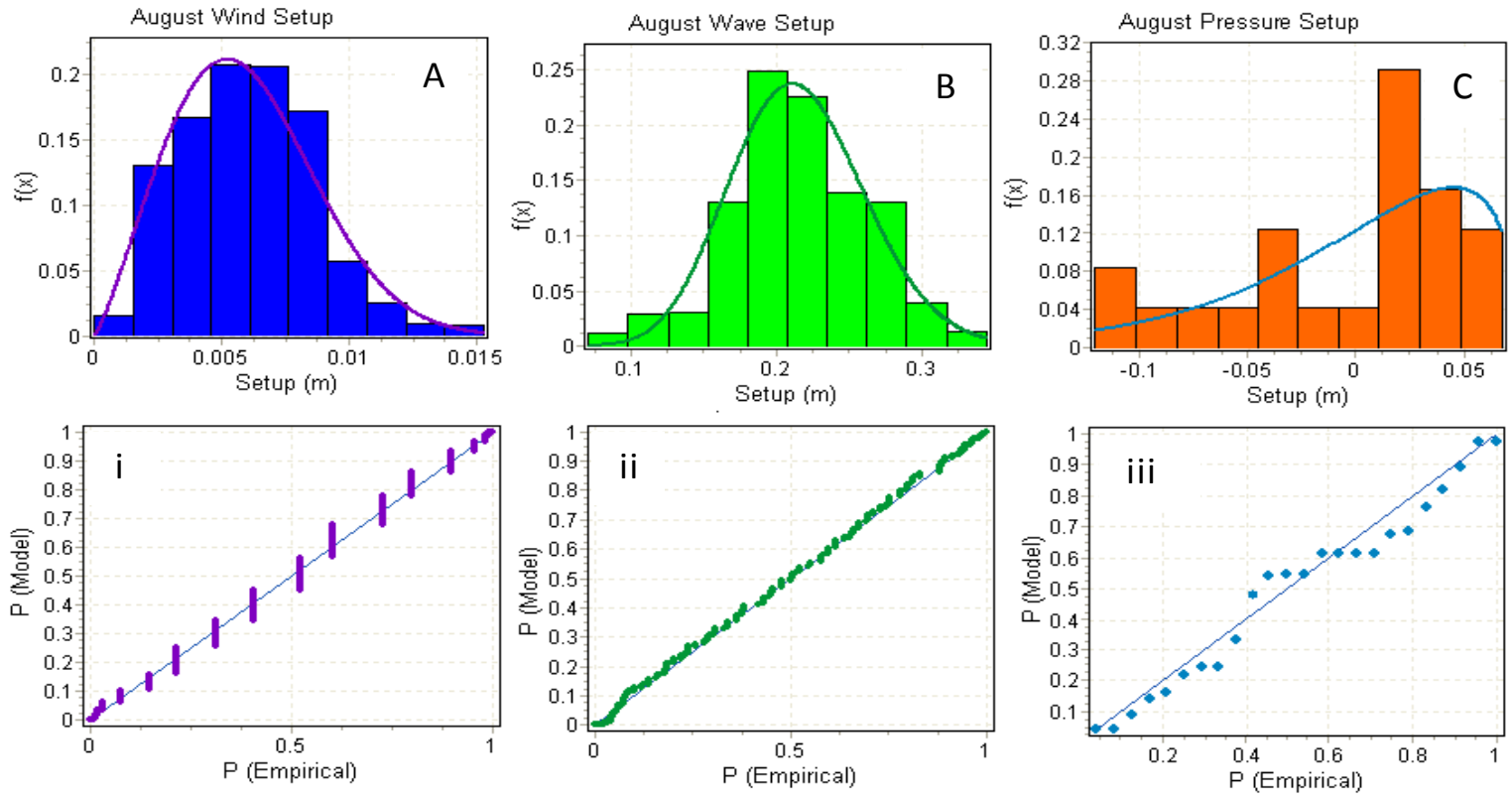

Figure 3. August probability density functions for wind setup (A), wave setup (B) and pressure setup (C) with the respective (i, ii, ii) p-p plots showing goodness of fit.

The step function nature of the distribution in the wind and pressure setup in Figures $2 \mathrm{~A}, 2 \mathrm{C}, 3 \mathrm{~A}$ and $3 \mathrm{C}$ are indicative of discrete or truncated values, but the general trends of the observed data generally follow the modelled data for the relevant fit.

The overall contributions from the simulation experiments give the following $\mathrm{pdfs}$ for the water level at the coast, above mean sea level for the combined wind, wave and pressure setup for February (Figure 4-left panel) and August (Figure 4-right panel):
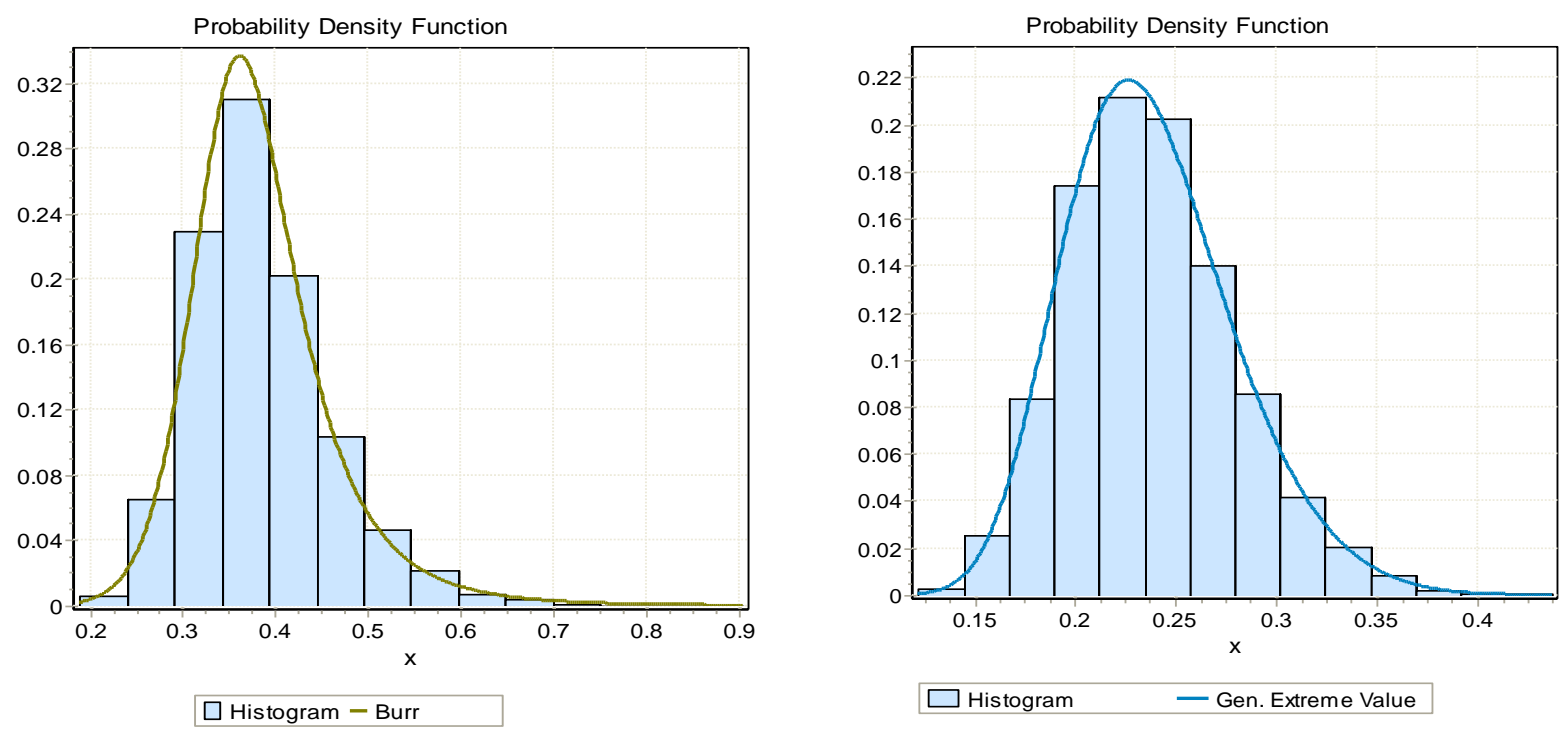

Figure 4. The simulated water level distributions and modelled distribution for February - the Burr distribution (left panel) and August - the Generalised Extreme Value dis tribution (right panel). 
The February pdf for the total water level from the combined WWP drivers is represented at the 0.05 level of significance by:

$$
f(x)=\frac{10.73\left(\frac{x}{0.36}\right)^{9.73}}{0.36\left(\left(1+\frac{x}{0.36}\right)^{10.73}\right)^{1.73}}
$$

and the estimates for the combined water level contribution for August is represented by:

$$
\begin{gathered}
f(x)=\frac{1}{0.04} \exp \left(-(1+0.14 z)^{\frac{1}{0.14}}\right)(1-0.14 z)^{-1+\frac{1}{0.14}} \\
\text { Where } \quad z=\frac{x-0.22}{0.04}
\end{gathered}
$$

The moments of the data for the respective distributions at a 0.05 level of significance are:

$\begin{array}{ccc} & \text { February } & \text { August } \\ \text { Mean } & 0.39 & 0.24 \\ \text { Mode } & 0.36 & 0.23 \\ \text { Standard Deviation } & 0.08 & 0.04\end{array}$

The mean and standard deviation for both months show a shift towards a lower water level from February to August. The modal values which are close to or same as the mean are indicative of the water levels being fairly regular at the mean values for the given month. The standard deviation which reflects the level of variability in the water levels is higher in February than in August (as indicated in Fig 3).

When the methodology is applied across the months for entire year for 2009, the modelled water levels closely follow the wave setup for the greater part of the rainy season (Figure 5), the contribution from the combined wind and pressure setup, termed here as the residual, is however larger during the dry season where the largest difference is during the month of February.
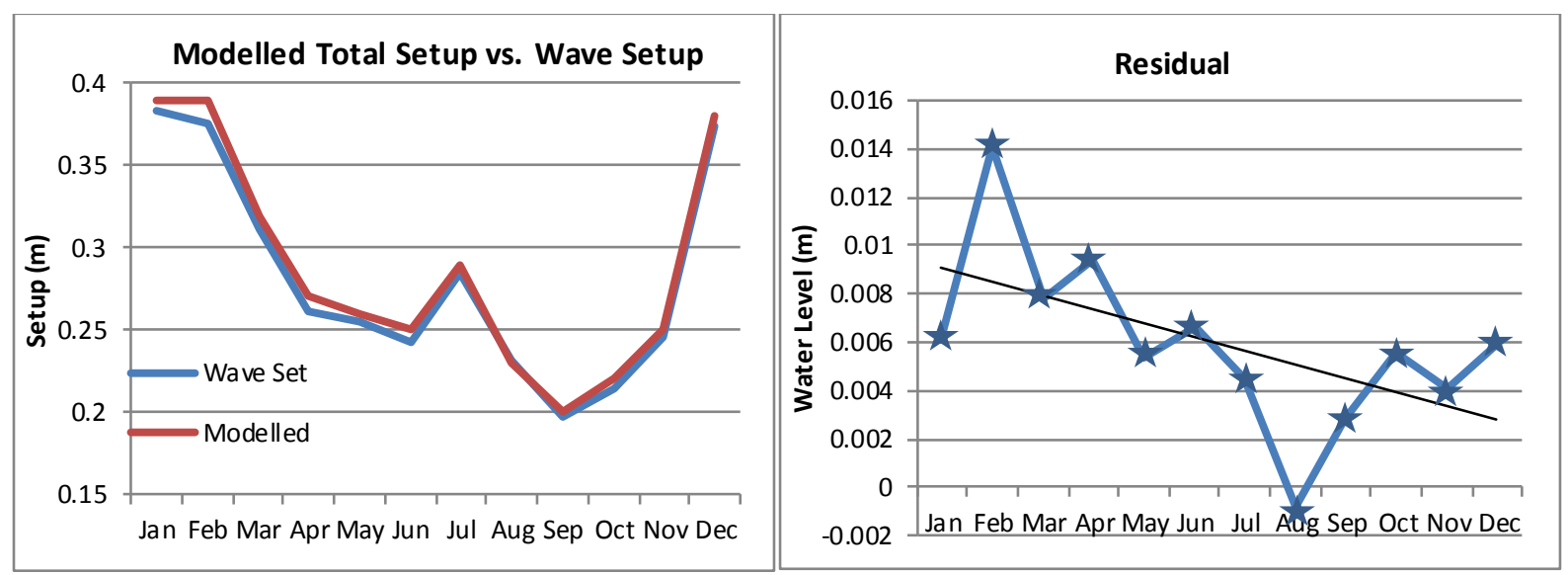

Figure 5. Wave Setup vs. combined setup for 2009 (left panel) and the residuals (difference between total coastal setup and combined $w$ ave setup) (right panel)

\section{DISCUSSION}

The development of the probability distributions for combined coastal setup from wind, wave and pressure driving forces has provided indications of a seasonal contribution of the combination. While the total coastal setup 
closely follows the trend of the wave setup as it is at least two orders of magnitude higher than the wind and pressure setup, the combined effects produce higher coastal water levels from setup in the dry season months. Additionally, while the total coastal setup is largely driven by wave setup, the wind setup and the IBR effect have a greater influence on the dry season months than during the rainy season.

While the peak in July (Figure 5) is not associated with any tropical cyclone activity, it appears to be an anomalously higher value than the average of the months. It is suggested here that a very long - running data set is needed to fully establish this anomaly (or not).

The modelled results are clearly dependent on the base data set and while the generation of a secondary data set effectively overcomes the limited data problem, the synthetic data set is heavily dependent on the sample data set, its distribution and statistical properties including the presence of outliers. It is noteworthy that the initial data set was not gap or error free. The time sequence was not entirely periodic and while care was taken to ensure that the base data was as accurate as possible including filling of data gaps by linear regression, there can be no substitute for missing data - an obvious limitation.

While the paucity of deep water nearshore wave data east of the Caribbean archipelago is acknowledged; in trying to accommodate the limited data set within the short time frame; the Monte Carlo approach has been shown with the method of random sampling to be effective in the provision of a huge quantity of synthetic data.

Additionally, since we seek to establish the base water level without the effects of tropical systems, this necessitates the removal or correction of the data for the period of the effect of these systems. The list-wise deletion method chosen here is a certain way to ensure no cross signals from extreme synoptic activity; the disadvantage is however that it results in the loss of data.

Despite the disadvantages, the method enables the development of a stochastic estimate of the combined contribution of the wind, wave and pressure setup parameters. This has enabled the moments of the different distributions to show that the combined setup for the dry season month to contribute to a higher coastal level than in the wet season month. Although the effect of El Niño on the coastal water level variation in the eastern Caribbean is not established it is noted here however, that 2009 was a moderate El Niño year (Null 2012) and it is probable that some of the variation may yet be externally forced by this phenomenon.

\section{CONCLUSION}

The use of the Monte Carlo simulation technique has provided estimates of the combined contribution of wind, wave and pressure setup to the total water level at the coast. While wave setup, wind setup and oceanic response to the inverted barometer effect have been previously examined individually, this study has shown that in the Caribbean region, the combined effect largely follows the wave setup. Although this is perhaps expected due to the difference in the order of magnitudes of the wave and wind-pressure setup, the wind-pressure setup has a greater contribution during the dry season than the greater part of the rainy season.

The total coastal setup in the Caribbean region, from the combined driving forces of winds, waves and atmospheric pressure show higher water levels at the coast during the December, January, February months with a general lowering trend from March to November.

\section{ACKNOWLEDGEMENTS}

We acknowledge the Department of Civil and Environmental Engineering, Faculty of Engineering, University of the West Indies, St. Augustine Campus and the French data authority, Météo-France for facilitating this work.

\section{REFERENCES}

Bacon, P. R. 1978. Flora and fauna of the Caribbean, an introduction to the ecology of the West Indies. Port of Spain, Trinidad: Key Caribbean Publications Ltd.

Berg, R. J., and L. A. Avila. 2010. "Atlantic Hurricane Season of 2009." Monthly Weather Review no. 139 (4):10491069. doi: 10.1175/2010mwr3476.1.

Bowen, A. J., D. L. Inman, and V. P. Simmons. 1968. "Wave Set-Down and Set-Up." J. Geophys. Res. no. 73 (8):2569-2577. doi: 10.1029/JB073i008p02569. 
Cambers, G. 1998. Coping with Beach Erosion. With Case Studies from the Caribbean, Coastal Management Sourcebooks 1. Paris: UNESCO Publishing.

Chelton, D. B., and D. B. Enfield. 1986. "Ocean Signals in Tide Gauge Records." J. Geophys. Res. no. 91 (B9):9081-9098. doi: 10.1029/JB091 iB09p09081.

Dattatri, J., H. Raman, and N. Jothi Shankar. 1979. "Height and Period Distributions for Waves off Mangalore Harbour; West Coast." J. Geophys. Res. no. 84 (C7):3767-3772. doi: 10.1029/JC084iC07p03767.

Davis, G. A., and P. Nielsen. 1988. Field measurement of wave set-up Paper read at 23rd International Conference on Coastal Engineering, at Malaga, Spain.

Dean, R. G., and T. L. Walton. 2010. "Wave Setup." In Handbook of Coastal and Ocean Engineering, edited by K. C. Young, 1-23. California, Los Angeles: World Scientific.

Dotsenko, S., and N. Miklashevskaya. 2007. "Transformation of the ocean level under a moving area of disturbances of atmospheric pressure." Physical Oceanography no. 17 (2):65-74. doi: 10.1007/s 11110-007-0006-8.

Fu, Lee-Lueng, and Greg Pihos. 1994. "Determining the response of sea level to atmospheric pressure forcing using TOPEX/POSEIDON data." J. Geophys. Res. no. 99 (C12):24633-24642. doi: 10.1029/94jc01647.

Greenwood, B., and P.D. Osborne. 1990. "Vertical and horizontal structure in cross -shore flows: An example of undertow and wave set up on a barred beach." Coastal Engineering no. 14:543-580.

Gui, S. , R. Zhang, and X. Xuzhang. 1998. "Overtopping Reliability Models for River Levee." Hydraulic Engineering no. 124 (12):8.

Guza, R. T., and E. B. Thornton. 1981. "Wave Set-Up on a Natural Beach." J. Geophys. Res. no. 86 (C5):41334137. doi: 10.1029/JC086iC05p04133.

Hansen, U. A 1978. "Wave Setup and Design Water Level." Journal of the Waterway Port Coastal and Ocean Division no. 104 (2):227-240.

Hanslow, D., and P. Nielsen 1993. "Shoreline set-up on natural beaches." Journal of Coastal Research no. SI (15):110 .

Harper, B. A., and R. J. Sobey. 1983. "Open-boundary conditions for open-coast hurricane storm surge." Coastal Engineering no. 7 (1):41-60. doi: 10.1016/0378-3839(83)90026-1.

Harris, D. L. 1963. "Characteristics of the Hurricane Storm Surge." Technical Paper no. 48: United States Weather Bureau, Washington, D.C.

Holman, R. A, and A. H Sallenger. 1985. "Setup and swash on a natural beach." Journal of Geophysical Research no. 90 (C1):945-953.

Inazu, D., N. Hirose, S. Kizu, and K. Hanawa. 2006. "Zonally Asymmetric Response of the Japan Sea to Synoptic Pressure Forcing." J. Oceanography no. 62:909-916.

Johnson, J. W. 1953. Proceedings of the fourth Conference on Coastal Engineering. Chicago, Illinois: Council on Wave Research, The Engineering Foundation.

King, B. A., M. W. L. Blackley, A. P. Carr, and P. J. Hardcastle. 1990. "Observations of Wave-induced Set-up on a Natural Beach." J. Geophys. Res. no. 95 (C12):22289-22297. doi: 10.1029/JC095i.

Kjerfve, B. 1994. Coastal Lagoon Processes. Edited by Bjorn Kjerfve, Elsevier Oceanography Series. The Netherlands: Elsevier Science B.V.

Komar, P. D. 1998. "Beach Processes and Sedimentation." Prentice Hall, Upper Saddle River, N.J., USA: 544pp.

Moran, T. J. 2008. Hydraulic Analysis: The Effect of Wind on Water. Consultant's Update (30): 6.

Nakamura et al., K. Monte Carlo Techniques. Particle Data Group 2012. Available from http://pdg.lbl.gov/2011/reviews/rpp2011-rev-monte-carlo-techniques.pdf.

Novak, P., V. Guinot, A. Jeffrey, and D. Reeve. 2010. Hydraulic Modelling:An Introduction: Principles, Methods and Applications. Abingdon, Oxon: Spon Press.

Null, J. 2012. "El Nino and La Nina years and intensities."

Saville, T., M. Asce, E. W. McClendon, A. L. Cochran, and F. Asce. 1962. Freeboard allowances for waves in inland reservoirs: American Society of Civil Engineers.

Stockdon, H. F., R. A. Holman, P. A. Howd, and A. H. Sallenger Jr. 2006. "Empirical parameterization of setup, swash, and runup." Coastal Engineering no. 53 (7):573-588. doi: 10.1016/j.coastaleng.2005.12.005.

TuDelft. 2011. Coastal and River Engineering Support System. Netherlands Ministry of Public Works (Rijkswaterstaat), IHE-Delft and TU-Delft 2010 [cited 10th November 2011]. Available from http://www.kennis bank-waterbouw.n1/cress/.

UNISYS. 2011. Unisys Weather 2011 [cited 2012 2011]. Available from http://weather.unisys.com/hurricane/.

Weigel, R. L. 1964. Oceanographical Engineering, Fluid Mechanics. Englewood Cliffs, N. J.: Prentice Hall.

Wunsch, C. 1972. "Bermuda Sea Level in relation to Tides, Weather and Barometric Fluctuations." Rev. Geophys. no. 10:1-49. 
Wunsch, Carl, and Detlef Stammer. 1997. "Atmospheric loading and the oceanic inverted barometer effect." Rev. Geophys. no. 35 (1):79-107. doi: 10.1029/96rg03037.

Yanagishima, S., and K. Katoh. 1990. Field observation on wave setup near the shoreline. Paper read at 22nd International Conference on Coastal Engineering, at New York, N.Y. 